\title{
Explicit Deconvolution of Well Test Data Dominated by Wellbore Storage
}

\author{
K. Razminia, ${ }^{1}$ A. Hashemi, ${ }^{1}$ A. Razminia, ${ }^{2}$ and D. Baleanu ${ }^{3,4,5}$ \\ ${ }^{1}$ Department of Petroleum Engineering, Petroleum University of Technology, Ahwaz, Iran \\ ${ }^{2}$ Dynamical Systems \& Control (DSC) Research Laboratory, Department of Electrical Engineering, School of Engineering, \\ Persian Gulf University, P. O. Box 75169, Bushehr, Iran \\ ${ }^{3}$ Department of Chemical and Materials Engineering, Faculty of Engineering, King Abdulaziz University, Jeddah, Saudi Arabia \\ ${ }^{4}$ Department of Mathematics and Computer Sciences, Faculty of Arts and Sciences, Çankaya University, 06530 Ankara, Turkey \\ ${ }^{5}$ Institute of Space Sciences, Magurele-Bucharest, Romania
}

Correspondence should be addressed to A. Razminia; a.razminia@gmail.com

Received 27 December 2013; Accepted 28 February 2014; Published 3 April 2014

Academic Editor: Abdon Atangana

Copyright ( $) 2014 \mathrm{~K}$. Razminia et al. This is an open access article distributed under the Creative Commons Attribution License, which permits unrestricted use, distribution, and reproduction in any medium, provided the original work is properly cited.

\begin{abstract}
This paper addresses some methods for interpretation of oil and gas well test data distorted by wellbore storage effects. Using these techniques, we can deconvolve pressure and rate data from drawdown and buildup tests dominated by wellbore storage. Some of these methods have the advantage of deconvolving the pressure data without rate measurement. The two important methods that are applied in this study are an explicit deconvolution method and a modification of material balance deconvolution method. In cases with no rate measurements, we use a blind deconvolution method to restore the pressure response free of wellbore storage effects. Our techniques detect the afterflow/unloading rate function with explicit deconvolution of the observed pressure data. The presented techniques can unveil the early time behavior of a reservoir system masked by wellbore storage effects and thus provide powerful tools to improve pressure transient test interpretation. Each method has been validated using both synthetic data and field cases and each method should be considered valid for practical applications.
\end{abstract}

\section{Introduction}

In conventional well test analysis, the pressure response to constant rate production is essential information that presents the distinct characteristics for a specific type of reservoir system. However, in many cases, it is difficult to acquire sufficient constant rate pressure response data. The recorded early time pressure data are often hidden by wellbore storage (variable sandface rates). In some cases, outer boundary effects may appear before wellbore storage effects disappear. Therefore, it is often imperative to restore the early time pressure response in the absence of wellbore storage effects to provide a confident well test interpretation [1-4].

A considerable amount of work has been done on multirate (variable) tests during the last 50 years. However, these are basically sequential constant rate drawdowns; only transient pressure is measured and rate is assumed to be constant during each drawdown test [5]. All these works deal with the direct problem. In other words, the constant rate solution (the influence or the unit response function) is convolved (superimposed) with the time dependent inner boundary condition to obtain solutions to the diffusivity equation. This process is called convolution. The process of determining the influence function is called deconvolution [6-8].

Based on [1], deconvolution is a technique used to convert measured pressure and sandface rate data into the constant rate pressure response of the reservoir. In other words, deconvolution provides the pressure response of a well/reservoir system free of wellbore storage effects, as if the reservoir is producing at a constant rate. Once the deconvolved pressure is obtained, conventional interpretation methods can be used for reservoir system identification and parameter estimation.

The purpose of the well test interpretation, as stated by Gringarten et al., [9] is to identify the system and determine 
its governing parameters from measured data in the wellbore and at the wellhead. This problem is known as the inverse problem. The solution of the inverse problem usually is not unique. Gringarten et al. [9] pointed out that if the number and the rage measurements increased, the nonuniqueness of the inverse problem will be reduced. Thus combining sandface flow rate with pressure measurements will enhance the conventional (including type curve) well test interpretation methods. On the other hand, mathematically, deconvolution is also a highly unstable inverse problem because small errors in the data can result in large uncertainties in the deconvolution solution $[10,11]$.

Unfortunately, standard deconvolution techniques require accurate measurements of flow rate and pressure at downhole (or sandface) conditions. While accurate pressure measurements are commonplace, the measurement of sandface flow rates is rare, essentially nonexistent in practice. As such, the deconvolution of wellbore storage distorted pressure test data is problematic. In theory, this process is possible, but in practice, without accurate measurements of flow rates, this process cannot be employed $[12,13]$.

In the past 50 years, a variety of deconvolution techniques have been proposed in petroleum engineering. Russell [14] used the approximate direct method to correct the pressure transient data distorted by wellbore storage into the equivalent pressure function for the constant rate case. Gladfelter et al. [15] and Fetkovich and Vienot [16] used the rate normalization techniques to correct for the wellbore storage effects. These rate normalization methods were successful in some cases. So Johnston [17] provided the material balance deconvolution that is a practical approach for the analysis of pressure transient data distorted by wellbore storage effects.

Essentially, rate normalization techniques and material balance deconvolution are restricted when the lack of rate measurement exists. van Everdingen [18] and Hurst [19] demonstrated empirically that the sandface flow rate profile can be modeled approximately using an exponential relation for the duration of wellbore storage distortion during a pressure transient test. The van Everdingen and Hurst exponential rate model is given in dimensionless form as

$$
q_{D}\left(t_{D}\right)=1-e^{-\beta t_{D}} .
$$

Further, they showed that the rate-time relationship during afterflow (for a pressure buildup test) or unloading (in a pressure drawdown test) is a function of the pressure drop change with respect to time and a relatively constant wellbore storage coefficient.

Based on a material balance in the wellbore, the sandface flow rate can be calculated by the following relation given in dimensionless form

$$
q_{D}\left(t_{D}\right)=1-C_{D} \frac{d p_{w D}}{d t_{D}},
$$

where it can be noted that, in the development of wellbore storage models solutions (e.g., type curves), a constant wellbore storage coefficient is always assumed.

Equations (1) and (2) laid the groundwork for $\beta$ deconvolution. Joseph and Koederitz [20] and Kuchuk [21] applied $\beta$-deconvolution for the analysis of wellbore storage distorted pressure transient data. The $\beta$-deconvolution formula, which computes the undistorted pressure drop function directly from the wellbore storage affected data, is given as

$$
p_{s D}\left(t_{D}\right)=\frac{1}{\beta} \frac{d p_{w D}\left(t_{D}\right)}{d t_{D}}+p_{w D}\left(t_{D}\right) .
$$

It should be noted that (3) is only valid when the sandface flow rate profile follows an exponential trend as prescribed by (1) [12]. In this work, we develop an approach that overcomes this restriction by treating the $\beta$ quantity as a variable in general, rather than a constant.

The obvious advantage of $\beta$-deconvolution is that the wellbore storage effects are eliminated and the restored pressure is obtained using only the given pressure data.

This paper reports a modification of Russell method (Appendix A), a modification of $\beta$-deconvolution, and an explicit deconvolution formula to restore the pressure and rate data, and a review on material balance deconvolution is also presented to deconvolve the pressure and rate data after the explicit deconvolution method. Then a general approach to analyze the deconvolution problem is provided (Appendix B). In verification examples section, we show the power and practical applicability of our approaches with various synthetic and field case examples for oil and gas wells.

\section{Main Results}

2.1. $\beta$-Deconvolution and Its Modification. van Everdingen and Hurst [22] presented the dimensionless wellbore pressure for a continuously varying flow rate as

$$
p_{w D}\left(t_{D}\right)=q_{D}(0) p_{s D}\left(t_{D}\right)+\int_{0}^{t_{D}} p_{D}^{\prime}(\tau) p_{s D}\left(t_{D}-\tau\right) d \tau .
$$

An alternative form to (4) can be obtained by integration by parts as

$$
p_{w D}\left(t_{D}\right)=q_{D}\left(t_{D}\right) p_{s D}(0)+\int_{0}^{t_{D}} q_{D}(\tau) p_{s D}^{\prime}\left(t_{D}-\tau\right) d \tau,
$$

where $p_{w D}\left(t_{D}\right)=(k h / 141.2 q B \mu)\left(p_{i}-p_{w f}(t)\right), t_{D}=$ $\left(0.0002637 k t / \phi \mu c_{t} r_{w}^{2}\right), p_{s D}=p_{D}+S, p_{w D}\left(t_{D}\right)$ is dimensionless wellbore pressure with wellbore storage and skin effects, $p_{D}\left(t_{D}\right)$ is dimensionless sandface pressure for the constant rate case without wellbore storage and skin effects, $S$ is steady state skin factor, $p_{s D}^{\prime}\left(t_{D}\right)=d p_{s D}\left(t_{D}\right) / d t_{D}, q_{D}\left(t_{D}\right)=$ $q_{s f}\left(t_{D}\right) / q_{r}, q_{D}^{\prime}\left(t_{D}\right)=d q_{D}\left(t_{D}\right) / d t_{D}$, and $q_{r}$ is reference flow rate, if the stabilized constant rate is available, then $q_{r}$ should be replaced by $q_{R}, q_{s f}(t)$ is variable sandface flow rate (flowmeter reading), and $q_{D}\left(t_{D}\right)$ is dimensionless sandface rate.

It should be emphasized that (4) and (5) can be applied for many reservoir engineering problems. The linearity of diffusivity equation allows us to use (4) and (5) for fractured, 
layered, anisotropic, and heterogeneous systems as long as the fluid in the reservoir is single phase. These equations can also be applied to both drawdown and buildup tests if the initial conditions are known. For a reservoir with an initial constant and uniform pressure distribution $\left(p_{D}(0)=0\right)$, (4) and (5) can be expressed as

$$
\begin{gathered}
p_{w D}\left(t_{D}\right)=\int_{0}^{t_{D}} q_{D}^{\prime}(\tau) p_{s D}\left(t_{D}-\tau\right) d \tau, \\
p_{w D}\left(t_{D}\right)=S q_{D}\left(t_{D}\right)+\int_{0}^{t_{D}} q_{D}(\tau) p_{s D}^{\prime}\left(t_{D}-\tau\right) d \tau .
\end{gathered}
$$

Furthermore, (6) and (7) also can be expressed as

$$
\begin{gathered}
p_{w D}\left(t_{D}\right)=\int_{0}^{t_{D}} q_{D}^{\prime}\left(t_{D}-\tau\right) p_{s D}(\tau) d \tau, \\
p_{w D}\left(t_{D}\right)=S q_{D}\left(t_{D}\right)+\int_{0}^{t_{D}} q_{D}\left(t_{D}-\tau\right) p_{s D}^{\prime}(\tau) d \tau .
\end{gathered}
$$

In (6) and (8), it is assumed that $q_{D}^{\prime}\left(t_{D}\right)$ exists. If $q_{D}\left(t_{D}\right)$ is constant, then (7) and (9) must be used. Equations (6) and (8) are known as a Volterra integral equation of first kind and the convolution type.

Taking the Laplace transform of (6) yields

$$
\bar{p}_{w D}(s)=s \bar{q}_{D}(s) \bar{p}_{s D}(s) .
$$

Rearranging (10) for the equivalent constant rate pressure drop function, $p_{s D}(s)$, we obtain

$$
\bar{p}_{s D}(s)=\frac{\bar{p}_{w D}(s)}{s \bar{q}_{D}(s)} .
$$

By taking the Laplace transform of (1), one can easily obtain:

$$
\bar{q}_{D}(s)=\frac{1}{s}-\frac{1}{s+\beta} .
$$

Substituting (12) into (11) and then taking the inverse Laplace transform of (11) yield the beta deconvolution formula:

$$
p_{s D}\left(t_{D}\right)=\frac{1}{\beta} p_{w D}^{\prime}\left(t_{D}\right)+p_{w D}\left(t_{D}\right),
$$

where

$$
p_{w D}^{\prime}\left(t_{D}\right)=\frac{d p_{w D}}{d t_{D}}
$$

where we note that (13) is specifically valid only for the exponential sandface flow rate profile given by (1). This may present a serious limitation in terms of practical application of the $\beta$-deconvolution method. To overcome this restriction, we propose an idea. It would be assumed that $\beta$ is not constant in general. If $q_{D}\left(t_{D}\right)$ data are given, the procedure is as follows:

$$
q_{D}\left(t_{D}\right)=1-e^{-\beta\left(t_{D}\right) t_{D}} .
$$

Rearranging (15) yields

$$
1-q_{D}\left(t_{D}\right)=e^{-\beta\left(t_{D}\right) t_{D}},
$$

then

$$
-\beta\left(t_{D}\right) t_{D}=\ln \left(1-q_{D}\left(t_{D}\right)\right),
$$

so

$$
\beta\left(t_{D}\right)=-\frac{\ln \left(1-q_{D}\left(t_{D}\right)\right)}{t_{D}} .
$$

Substituting of (18) into (13) instead of $\beta$ term yields the modified $\beta$-deconvolution:

$$
p_{s D}\left(t_{D}\right)=\frac{1}{\beta\left(t_{D}\right)} p_{w D}^{\prime}\left(t_{D}\right)+p_{w D}\left(t_{D}\right) .
$$

Plot of (19) versus $\left(\int_{0}^{t_{D}} q_{D}(\tau) d \tau / q_{D}\left(t_{D}\right)\right)$ and $\left(\int_{0}^{t_{D}}(1-\right.$ $\left.\left.q_{D}(\tau)\right) d \tau / 1-q_{D}\left(t_{D}\right)\right)$ for drawdown and buildup tests, respectively, should be considered more accurate to use as a practical tool for field applications. As mentioned before, the variable $\beta$ quantity (rather than a constant) shows the general and more accurate behavior of $q_{D}\left(t_{D}\right)$. So accuracy of (19) is also more than (13). It can be emphasized that (13) and (19) are applicable in the wellbore storage duration, and for the later times, the given pressure data are correct. However, the results of (19) show that this equation is not bad for the later times.

2.2. Explicit Deconvolution Formula. A few types of approximation functions can be used to approximate $q_{D}\left(t_{D}\right)$. An approximate proof is given here to show that the exponential function gives a good representation of $q_{D}\left(t_{D}\right)$. By setting

$$
\begin{gathered}
q_{D}\left(t_{D}\right)=1-f\left(t_{D}\right), \\
f(0)=1 .
\end{gathered}
$$

Equation (21) is an initial condition for (20).

Taking the time derivative of (20) gives

$$
q_{D}^{\prime}\left(t_{D}\right)=-f^{\prime}\left(t_{D}\right) .
$$

Taking the time derivative of (2) gives

$$
q_{D}^{\prime}\left(t_{D}\right)=-C_{D} p_{w D}^{\prime \prime}
$$

From (2) and (20), we have

$$
f\left(t_{D}\right)=C_{D} p_{w D}^{\prime}
$$

And from (22) and (23), we have

$$
f^{\prime}\left(t_{D}\right)=C_{D} p_{w D}^{\prime \prime}
$$

After dividing right and left hand sides of (25) by (24), the result is

$$
\frac{f^{\prime}\left(t_{D}\right)}{f\left(t_{D}\right)}=\frac{p_{w D}^{\prime \prime}\left(t_{D}\right)}{p_{w D}^{\prime}\left(t_{D}\right)}
$$

Integrating both sides of (26) with respect to $t_{D}$ from 0 to $t_{D}$ yields

$$
\int_{0}^{t_{D}} \frac{f^{\prime}(\tau)}{f(\tau)} d \tau=\int_{0}^{t_{D}} \frac{p_{w D}^{\prime \prime}(\tau)}{p_{w D}^{\prime}(\tau)} d \tau
$$


Using elementary calculus yields

$$
\left.\ln (|f(\tau)|)\right|_{0} ^{t_{D}}=\ln \left(\left|f\left(t_{D}\right)\right|\right)-\ln (1)=\int_{0}^{t_{D}} \frac{p_{w D}^{\prime \prime}(\tau)}{p_{w D}^{\prime}(\tau)} d \tau .
$$

So

$$
f\left(t_{D}\right)=e^{\alpha\left(t_{D}\right)}
$$

where

$$
\alpha\left(t_{D}\right)=\int_{0}^{t_{D}} \frac{p_{w D}^{\prime \prime}(\tau)}{p_{w D}^{\prime}(\tau)} d \tau
$$

Now, the explicit deconvolution of data based on (20) can be written as follows:

$$
p_{s D}\left(t_{D}\right)=-\frac{1}{\alpha\left(t_{D}\right) / t_{D}} p_{w D}^{\prime}+p_{w D}\left(t_{D}\right),
$$

or

$$
p_{s D}\left(t_{D}\right)=-\frac{t_{D}}{\alpha\left(t_{D}\right)} p_{w D}^{\prime}+p_{w D}\left(t_{D}\right)
$$

that is similar to (19). The other similarity between (19) and (32) is that the plot of (32) versus $\left(\int_{0}^{t_{D}} q_{D}(\tau) d \tau / q_{D}\left(t_{D}\right)\right)$ and $\left(\int_{0}^{t_{D}}\left(1-q_{D}(\tau)\right) d \tau /\left(1-q_{D}\left(t_{D}\right)\right)\right)$ for drawdown and buildup tests, respectively, yields the more accurate results and is usable for practical applications. The applicability of (32) is also for duration of wellbore storage effects. And for the other times, the given pressure data are correct. However, using this method for the later times yields not bad results.

\section{Material Balance Deconvolution}

Material balance deconvolution is an extension of the rate normalization method. Johnston [17] defines a new $x$-axis plotting function (material balance time) that provides an approximate deconvolution of the variable rate pressure transient problem. There are numerous assumptions associated with the material balance deconvolution methods; one of the most widely accepted assumptions is that the rate profile must change smoothly and monotonically. In practical terms, this condition should be met for the wellbore storage problem.

The general form of material balance deconvolution is provided for the pressure drawdown case in terms of the material balance time function and the rate-normalized pressure drop function. The material balance time function is given as

$$
t_{m b}=\frac{N_{p}}{q_{D}(t)}
$$

where

$$
N_{p}=\int_{0}^{t} q_{D}(\tau) d \tau
$$

The rate-normalized pressure drop function is given by

$$
\frac{\Delta p_{w f}(t)}{q_{D}(t)}=\frac{p_{i}-p_{w f}(t)}{q_{D}(t)}
$$

The material balance time function for the pressure buildup case is given as

$$
t_{m b}=\frac{N_{p}}{1-q_{D}(\Delta t)}
$$

where

$$
N_{p}=\int_{0}^{\Delta t}\left(1-q_{D}(\tau)\right) d \tau
$$

The rate-normalized pressure drop function for the pressure buildup case is given as

$$
\frac{\Delta p_{w s}(\Delta t)}{1-q_{D}(\Delta t)}=\frac{p_{w s}(\Delta t)-p_{w f}(\Delta t=0)}{1-q_{D}(\Delta t)} .
$$

\section{Methodology}

In this work several methods are provided to restore the pressure data without any sandface flow rate information. The values of sandface flow rate data for all methods that require these data may be obtained from (20). We evaluated a very old correction method by Russell [14]. However, we modified this method by least square method, but it was found that this method is to be unacceptable for all applications. The derivation of this method and its modification is given in Appendix A.

The $\beta$-deconvolution and its modification are another technique that is mentioned in this study. The formulation of this method is presented in Section 2.1. The other explicit deconvolution method is an approach similar to the modified $\beta$-deconvolution that uses only the pressure data for deconvolution of pressure and rate data. The formulation of this method was derived in Section 2.2. The $\beta$-deconvolution, its modification, and explicit deconvolution formula can be used for practical applications. The applicability of these methods is for duration of wellbore storage effects. However, using these approaches for the other times yields not bad results.

The other technique is material balance deconvolution method [17] that has sufficiently accurate results. This method can also be used as a good approach for practical applications. The formulas for this method were given in Section 3.

In Appendix B, deconvolution is expressed as an inverse problem that is analyzed by a tricky idea. Based on this idea, an interesting proof is given for rate normalization method and material balance deconvolution that is a good approach to find the errors and limitations of these methods and overcome them. 


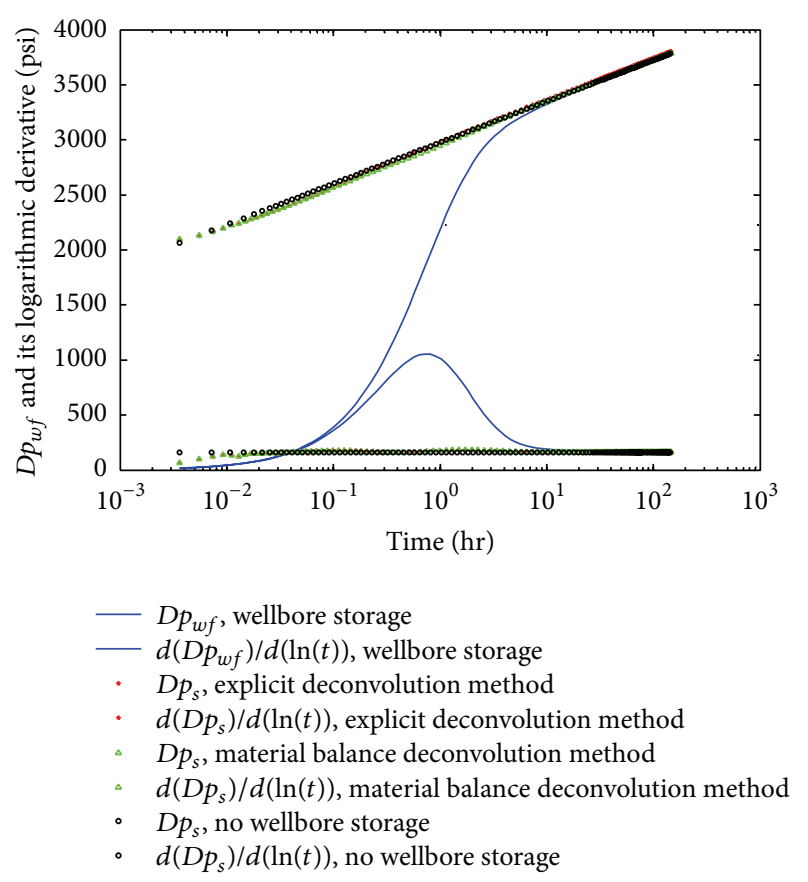

Figure 1: Deconvolution for a drawdown test in a homogeneous reservoir.

From the above-mentioned methods, we use the following two techniques to show the verification of these approaches.

Explicit Deconvolution Formula. The final result of explicit deconvolution method is given as follows:

$$
p_{s D}\left(t_{D}\right)=-\frac{t_{D}}{\alpha\left(t_{D}\right)} p_{w D}^{\prime}+p_{w D}\left(t_{D}\right)
$$

Plotting of this term versus $\left(\int_{0}^{t_{D}} q_{D}(\tau) d \tau / q_{D}\left(t_{D}\right)\right)$ and $\left(\int_{0}^{t_{D}}\left(1-q_{D}(\tau)\right) d \tau /\left(1-q_{D}\left(t_{D}\right)\right)\right)$ for drawdown and buildup tests, respectively, yields more accurate results. This approach performs well in field applications.

Material Balance Deconvolution. The material balance pressure drop function for the pressure drawdown test is given as

$$
\frac{\Delta p_{w f}(t)}{q_{D}(t)}=\frac{p_{i}-p_{w f}(t)}{q_{D}(t)}
$$

and the material balance time function for the pressure drawdown test is given as

$$
t_{m b}=\frac{\int_{0}^{t_{D}} q_{D}(\tau) d \tau}{q_{D}(t)} .
$$

For the buildup test, the material balance pressure drop function can be written as

$$
\frac{\Delta p_{w s}(\Delta t)}{1-q_{D}(\Delta t)}=\frac{p_{w s}(\Delta t)-p_{w f}(\Delta t=0)}{1-q_{D}(\Delta t)} .
$$

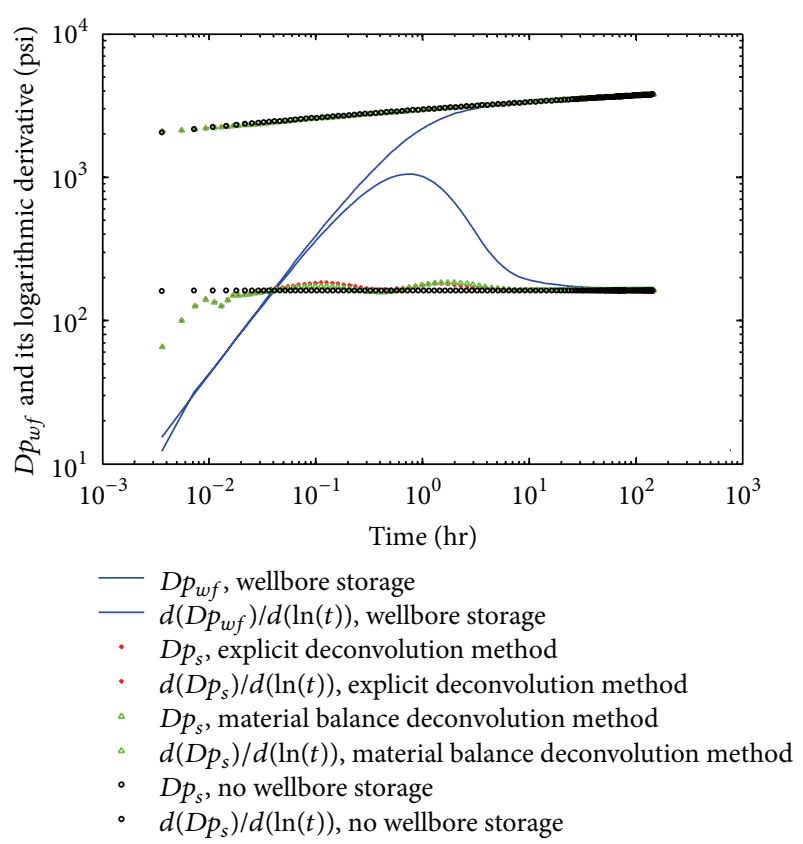

FIgURE 2: Deconvolution for a drawdown test in a homogeneous reservoir.

And the material balance time function can be written as

$$
t_{m b}=\frac{\int_{0}^{t_{D}}\left(1-q_{D}(\tau)\right) d \tau}{1-q_{D}(\Delta t)} .
$$

This technique is a good approach for practical applications.

\section{Verification Examples}

We first use few synthetic cases for different reservoir/wellbore systems to validate the applicability of explicit deconvolution formula and material balance deconvolution method. Then the field applications of these techniques will be shown by two real cases. The unloading rates are calculated with (20).

The first case is a synthetic test derived from a test design in a vertical oil well. The reservoir is homogenous and infinite acting with a constant wellbore storage. The wellbore storage coefficient is $C_{s}=0.015 \mathrm{bbl} / \mathrm{psi}$. The pressure data are obtained from the cylindrical source solution (test design).

We used the explicit deconvolution formula and material balance deconvolution method to deconvolve the pressure and unloading rate distorting by wellbore storage effects. The results are presented in Figures 1 and 2 for the semilog and log-log plots in the case of drawdown test and Figures 3 and 4 for the semilog and log-log plots in the case of buildup test. Besides the deconvolved pressures and their logarithmic derivatives, pressure responses with and without wellbore storage are also plotted on the figures for comparison. Through the deconvolution process, we have successfully removed the wellbore storage effects so that radial flow can be identified at early test times. The deconvolved pressures and their logarithmic derivatives are almost identical to 


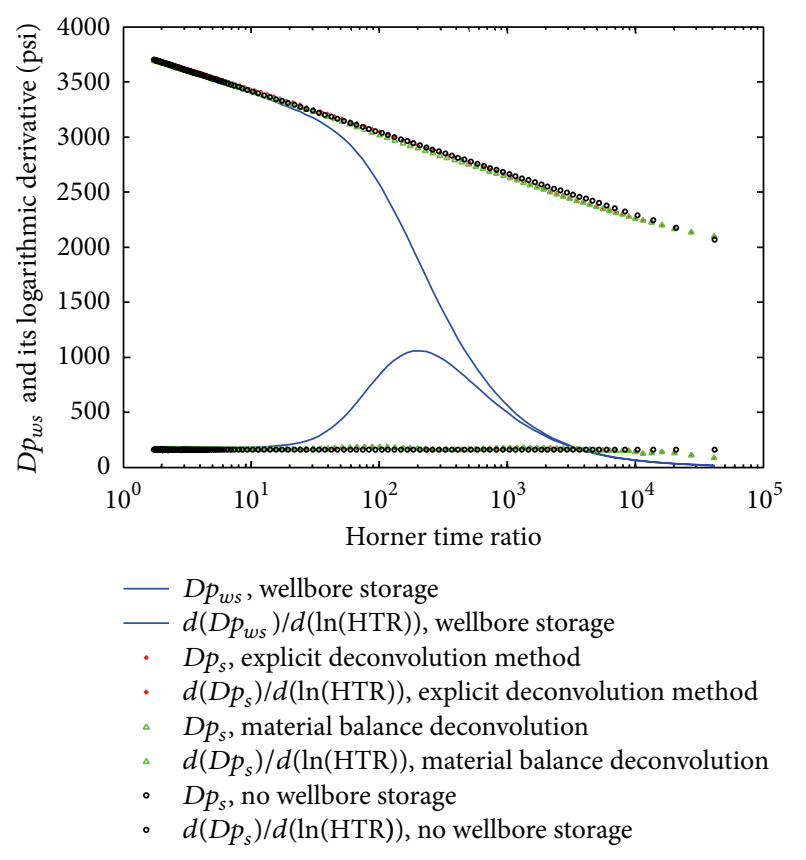

FIGURE 3: Deconvolution for a buildup test in a homogeneous reservoir.

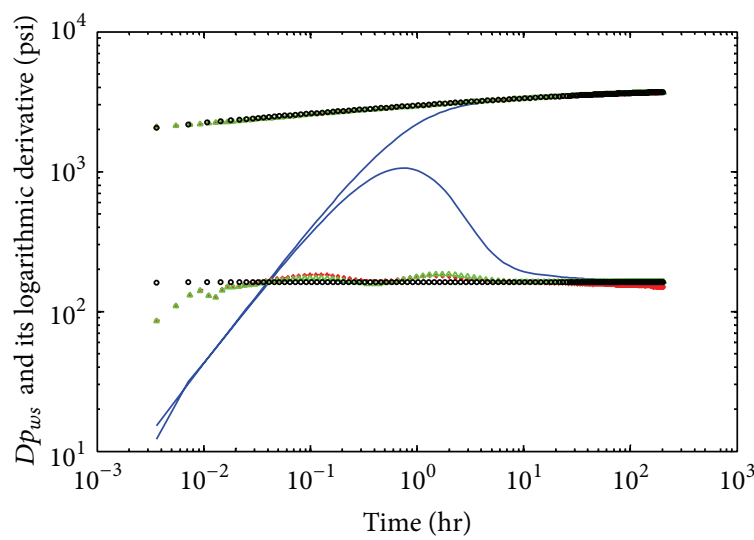

\begin{tabular}{ll}
- & $D p_{w s}$, wellbore storage \\
\hline & $d\left(D p_{w s}\right) / d(\ln (\mathrm{HTR}))$, wellbore storage \\
& $D p_{s}$, explicit deconvolution method \\
$\cdot$ & $d\left(D p_{s}\right) / d(\ln (\mathrm{HTR}))$, explicit deconvolution method \\
& $D p_{s}$, material balance deconvolution \\
$\therefore \quad$ & $d\left(D p_{s}\right) / d(\ln (\mathrm{HTR}))$, material balance deconvolution \\
- & $D p_{s}$, no wellbore storage \\
- $\quad$ & $d\left(D p_{s}\right) / d(\ln (\mathrm{HTR}))$, no wellbore storage
\end{tabular}

Figure 4: Deconvolution for a buildup test in a homogeneous reservoir.

the analytic solutions (without wellbore storage), which enables us to estimate reservoir parameters accurately.

The second case is an oil well drawdown test in a dual porosity reservoir. The storativity ratio $(\omega)$ and interporosity flow coefficient $(\lambda)$ are assumed to be 0.1 and $10^{-6}$, respectively. The constant wellbore storage coefficient is $C_{s}=0.15 \mathrm{bbl} / \mathrm{psi}$. The dimensionless wellbore pressure

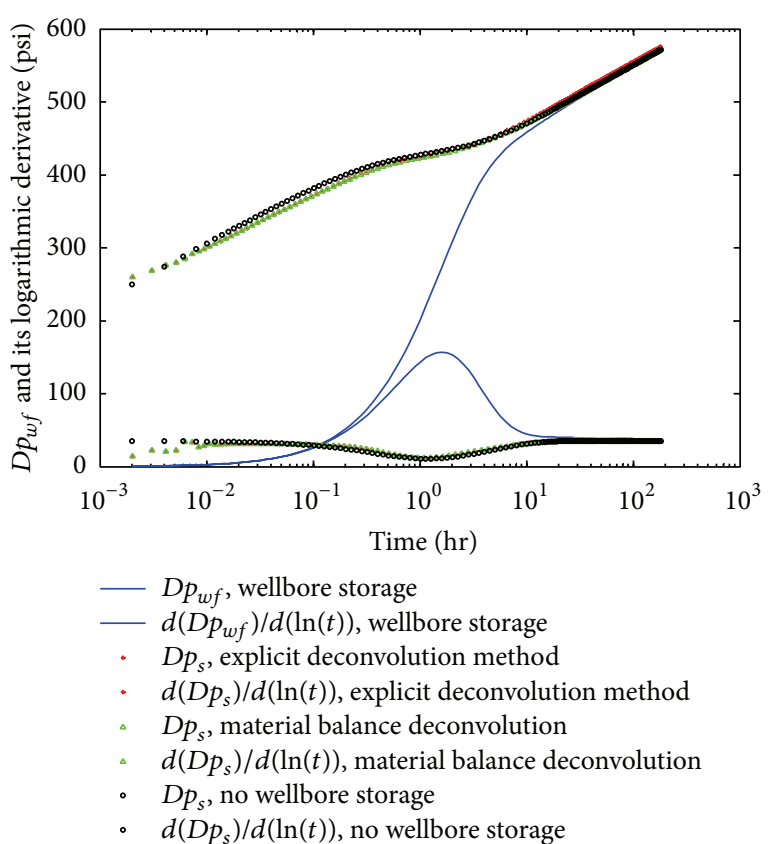

Figure 5: Deconvolution for a drawdown test in a dual porosity reservoir.

data were obtained from the cylindrical source solution with pseudosteady-state interporosity flow (test design). It is not possible to identify the dual porosity behavior characteristic of the reservoir from wellbore pressure data because this behavior has been masked completely by wellbore storage, as indicated in Figures 5 and 6.

We deconvolved the pressure and unloading rate and present the results in Figures 5 and 6 . The deconvolved results are reasonably consistent with the analytical solution. After deconvolution, the dual porosity behavior can be identified easily from the valley in the logarithmic derivative of pressure. If wellbore storage effects were not removed at early times, it easily could have incorrectly identified the reservoir system as infinite acting. The estimation of reservoir parameters can be obtained now from deconvolved pressure.

The third case is an oil well drawdown test in a reservoir with a sealing fault $250 \mathrm{ft}$ from the well. Synthetic pressure responses were generated by simulation (test design) with a constant wellbore storage coefficient of $0.1 \mathrm{bbl} / \mathrm{psi}$. As we can see in Figures 7 and 8, the early time infinite acting reservoir behavior has been masked completely by wellbore storage.

To recover the hidden reservoir behavior, we performed deconvolution on the pressure change to remove the wellbore storage effect. As in Figures 7 and 8, the deconvolved pressure change and logarithmic derivative data are almost identical to the responses without wellbore storage. The deconvolution results clearly indicate parallel horizontal lines for the logarithmic derivative. However, without wellbore storage effects elimination, this may mislead to identify the reservoir system as infinite acting. So this allows us to correctly identify the reservoir system having a sealing fault.

The fourth case is a field example that is taken from the literature [23]. The basic reservoir and fluid properties are 
TABLE 1: Reservoir rock and fluid properties for the first field case.

\begin{tabular}{lccccccc}
\hline$t_{p}(\mathrm{hr})$ & $h(\mathrm{ft})$ & $r_{w}(\mathrm{ft})$ & $q_{o}(\mathrm{STB} / \mathrm{D})$ & $B_{o}(\mathrm{RB} / \mathrm{STB})$ & $c_{t}\left(\mathrm{psi}^{-1}\right)$ & $\mu_{o}(\mathrm{cp})$ & $\phi$ \\
\hline 15.33 & 107 & 0.29 & 174 & 1.06 & $4.2 \times 10^{-6}$ & 2.5 & 0.25 \\
\hline
\end{tabular}

TABLE 2: Reservoir rock and fluid properties for the second field case.

\begin{tabular}{cccccccccccc}
\hline$t_{p}(\mathrm{hr})$ & $h(\mathrm{ft})$ & $r_{w}(\mathrm{ft})$ & $T\left({ }^{\circ} \mathrm{F}\right)$ & $\bar{p}(\mathrm{psi})$ & $q_{o}(\mathrm{STB} / \mathrm{D})$ & $q_{g}(\mathrm{Mscf} / \mathrm{D})$ & $c_{f}\left(\mathrm{psi}^{-1}\right)$ & $T_{d p}\left({ }^{\circ} \mathrm{F}\right)$ & $p_{d p}(\mathrm{psi})$ & ${ }^{\circ} \mathrm{API}$ & $\gamma_{g}$ \\
\hline 14.3111 & 100 & 0.354 & 279.5 & 7322 & 104 & 13925 & $3 \times 10^{-6}$ & 212 & 5445 & 45.375 & 0.68 \\
\hline
\end{tabular}

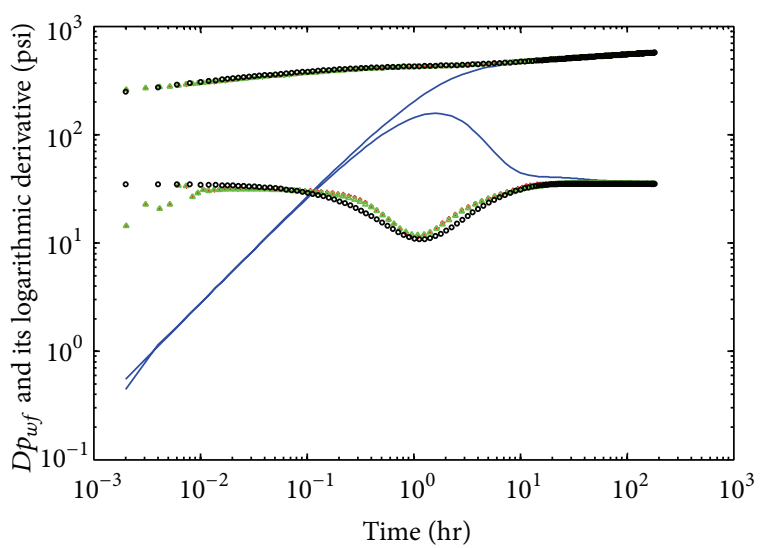

\begin{tabular}{ll}
- & $D p_{w f}$, wellbore storage \\
\hline & $d\left(D p_{w f}\right) / d(\ln (t))$, wellbore storage \\
& $D p_{s}$, explicit deconvolution method \\
- & $d\left(D p_{s}\right) / d(\ln (t))$, explicit deconvolution method \\
$\therefore \quad$ & $D p_{s}$, material balance deconvolution \\
.$\quad$ & $d\left(D p_{s}\right) / d(\ln (t))$, material balance deconvolution \\
- $\quad$ & $D p_{s}$, no wellbore storage \\
- & $d\left(D p_{s}\right) / d(\ln (t))$, no wellbore storage
\end{tabular}

Figure 6: Deconvolution for a drawdown test in a dual porosity reservoir.

shown in Table 1. In this case we provide the deconvolved pressure data using the explicit deconvolution formula and the material balance deconvolution method that is presented in this work. The data are taken from a pressure buildup test and can be reasonably used as field data. The deconvolution results are shown in Figure 9 in semilog plot. As it is illustrated from Figure 9, the corrected pressure provides a clear straight line starting as early as 1.5 hours, in contrast to the vague line from the uncorrected pressure response.

And the last (field) example is a gas condensate well buildup test following a variable rate production history. The duration of last pressure buildup test is 36.1556 hours (from 188.9 to 225.0556 hours). The basic reservoir and fluid properties for the last drawdown test are shown in Table 2. However, the properties of other production tests are not shown here. To use our new techniques effectively for gas wells, we use normalized pseudopressure and pseudotime functions as defined by Meunier et al. [24]. The final results of explicit deconvolution formula and material balance deconvolution method show two different slopes (Figure 10) where the early times slope is greater than the last one. This identifies the radial composite behavior of the reservoir. With the corrected pressures, the reservoir parameters can also be estimated.

\section{Conclusions}

In this work we have provided some explicit deconvolution methods for restoration of constant rate pressure responses from measured pressure data dominated by wellbore storage effects, without sandface rate measurements. Based on our investigations, we can state the following specific conclusions related to these techniques.

(1) The results obtained from the synthetic and field examples show the practical and computational efficiency of our deconvolution methods.

(2) Modification of $\beta$-deconvolution is presented where the beta quantity is variable, rather than a constant.

(3) For situations in which there are no downhole rate measurements, the explicit deconvolution methods (blind deconvolution approaches) can be used to derive the downhole rate function from the pressure measurements and restore the reservoir pressure response.

(4) We can unveil the early time behavior of a reservoir system masked by wellbore storage effects using these new approaches. Wellbore geometries and reservoir types can be identified from this restored pressure data. Furthermore, the conventional methods can be used to analyze this restored formation pressure to estimate formation parameters. So the presented techniques can be used as the practical tools to improve pressure transient test interpretation.

(5) Deconvolution in well test analysis is often expressed as an inverse problem. This approach can be used as an idea to justify the rate normalization method and the material balance deconvolution method.

\section{Appendices}

\section{A. Russel Method and Its Modification}

A method for correcting pressure buildup pressure data free of wellbore storage effects at early times has been developed by Russell [14]. In this method it is not necessary to measure the rate of influx after closing in at the surface. Instead, one uses a theoretical equation, which gives the form that the bottom hole pressure should have fluid accumulates in the 


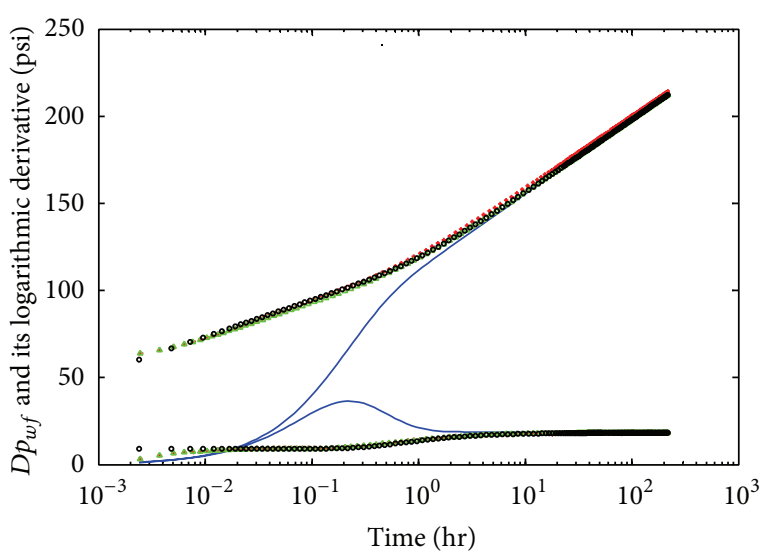

\begin{tabular}{ll}
- & $D p_{w f}$, wellbore storage \\
\hline & $d\left(D p_{w f}\right) / d(\ln (t))$, wellbore storage \\
& $D p_{s}$, explicit deconvolution method \\
$\cdot$ & $d\left(D p_{s}\right) / d(\ln (t))$, explicit deconvolution method \\
$\therefore$ & $D p_{s}$, material balance deconvolution \\
.$\quad$ & $d\left(D p_{s}\right) / d(\ln (t))$, material balance deconvolution \\
- $\quad$ & $D p_{s}$, no wellbore storage \\
- & $d\left(D p_{s}\right) / d(\ln (t))$, no wellbore storage
\end{tabular}

FIGURE 7: Deconvolution for a drawdown test in a reservoir with a sealing fault.

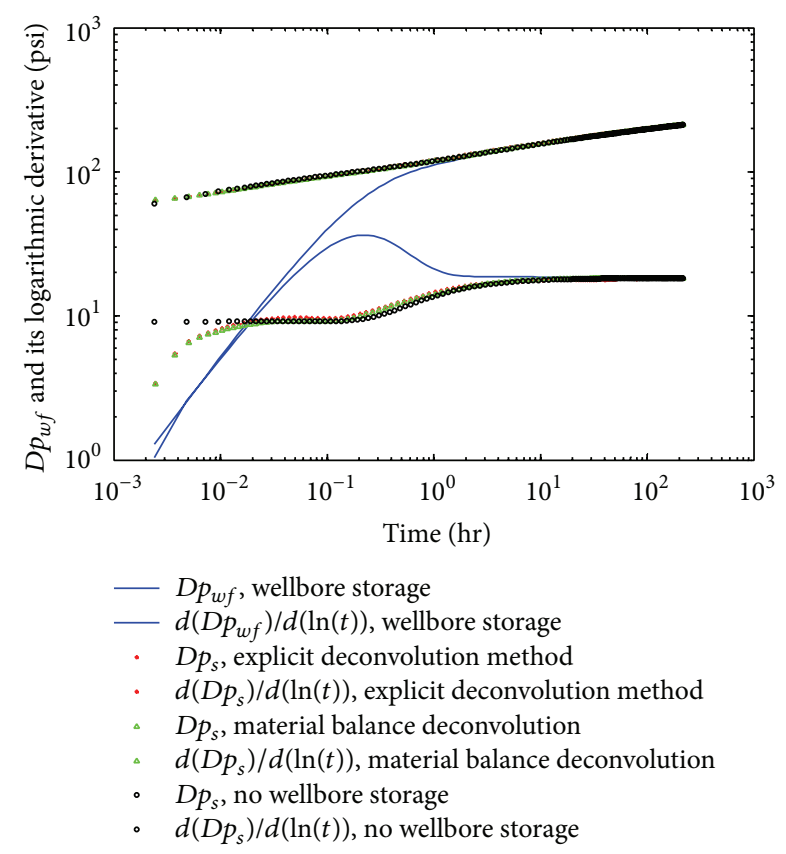

FIGURE 8: Deconvolution for a drawdown test in a reservoir with a sealing fault.

wellbore during buildup. This leads to the result that one should plot

$$
\frac{\left[p_{w s}(\Delta t)-p_{w f}(\Delta t=0)\right]}{\left[1-\left(1 / C_{2} \Delta t\right)\right]}
$$

versus $\log (\Delta t)$ in analyzing pressure buildup data during the early fill-up period. The denominator makes a correction for

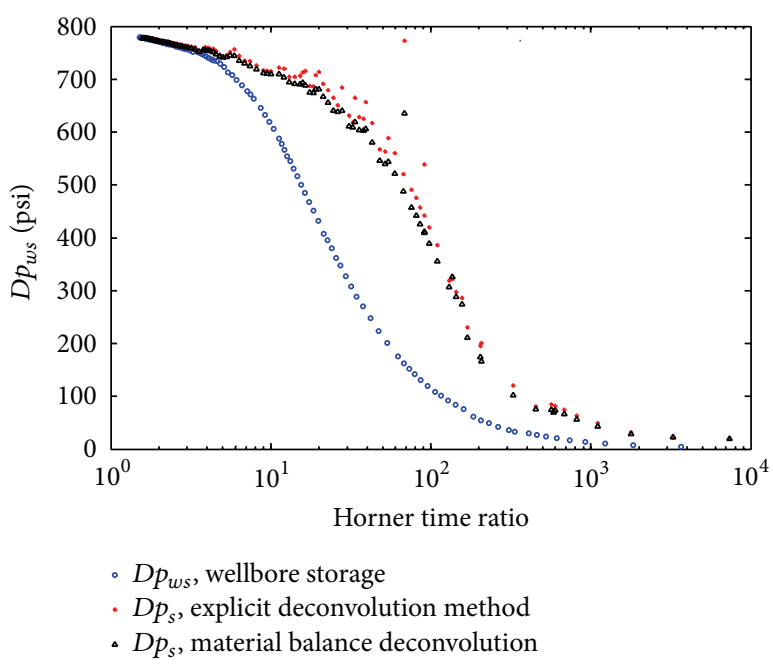

FIGURE 9: Restored pressures for a buildup test in a homogeneous reservoir.

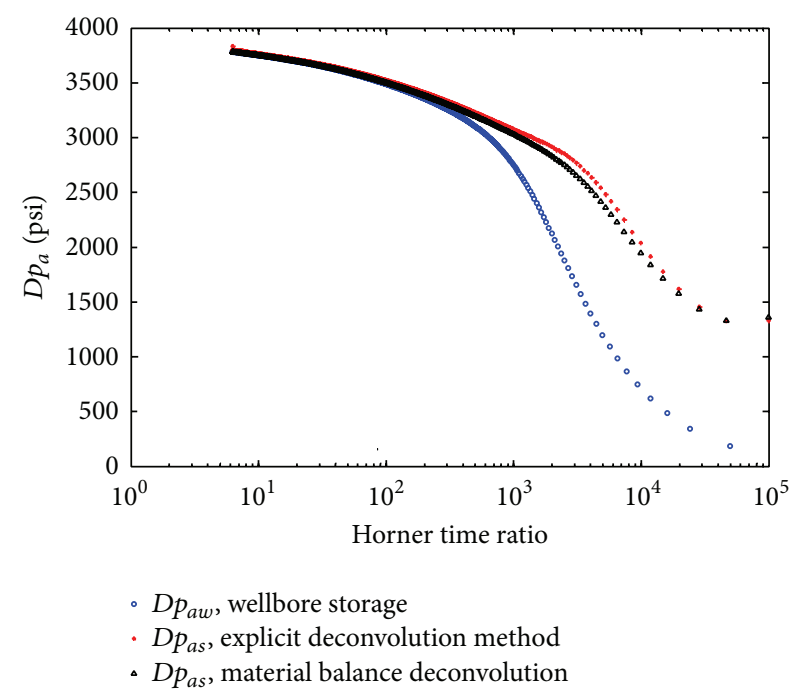

FIGURE 10: Restored pressures for a buildup test in a radial composite reservoir.

the gradually decreasing flow into the wellbore. The quantity $\mathrm{C}_{2}$ is obtained by trial and error as the value which makes the curve straight at early times. After obtaining the straight line section, the rest of the analysis is the same as for any other pressure buildup. This method has the advantage or requires no additional data over that taken routinely during a shut in test.

Due to the time consuming and unconfident of trial and error to determine $C_{2}$ in Russell method, we modify this method. Russell's wellbore storage correction is given as

$$
\frac{\left[p_{w s}(\Delta t)-p_{w f}(\Delta t=0)\right]}{\left[1-\left(1 / C_{2} \Delta t\right)\right]}=f(\Delta t=1 \mathrm{hr})+m_{s l} \log (\Delta t) .
$$


Defining the following function and using least squares technique obtain the final result:

$$
\begin{aligned}
& E\left(C_{2}, f, m\right) \\
& =\sum_{i=1}^{N}\left(\frac{\Delta p_{w s i}}{\left(1-\left(1 / C_{2} \Delta t_{i}\right)\right)}-f\left(C_{2}\right)-m\left(C_{2}\right) \log \left(\Delta t_{i}\right)\right)^{2} .
\end{aligned}
$$

To minimize the function $E$, it can differentiate $E$ with respect to $C_{2}, f$, and $m$ and setting the results equal to zero. After differentiation, it reduces to

$$
\begin{aligned}
\frac{\partial E}{\partial C_{2}}=-2 \sum_{i=1}^{N}\left\{\left(\frac{\Delta p_{w s i}}{\Delta t_{i}\left(C_{2}-\left(1 / \Delta t_{i}\right)\right)^{2}}\right)\right. \\
\times\left(\frac{\Delta p_{w s i}}{\left(1-\left(1 / C_{2} \Delta t_{i}\right)\right)}-f\left(C_{2}\right)\right. \\
\left.\left.-m\left(C_{2}\right) \log \left(\Delta t_{i}\right)\right)\right\}=0,
\end{aligned}
$$

$\frac{\partial E}{\partial f}$

$$
\begin{aligned}
& =-2 \sum_{i=1}^{N}\left(\frac{\Delta p_{w s i}}{\left(1-\left(1 / C_{2} \Delta t_{i}\right)\right)}-f\left(C_{2}\right)-m\left(C_{2}\right) \log \left(\Delta t_{i}\right)\right) \\
& =0
\end{aligned}
$$

$\frac{\partial E}{\partial m}$

$$
\begin{array}{r}
=-2 \sum_{i=1}^{N}\left\{\operatorname { l o g } ( \Delta t _ { i } ) \left(\frac{\Delta p_{w s i}}{\left(1-\left(1 / C_{2} \Delta t_{i}\right)\right)}-f\left(C_{2}\right)\right.\right. \\
\left.\left.-m\left(C_{2}\right) \log \left(\Delta t_{i}\right)\right)\right\}=0 .
\end{array}
$$

From (A.4), we define the following function:

$$
\begin{aligned}
& X\left(C_{2}\right) \\
& =\sum_{i=1}^{N}\left\{\left(\frac{\Delta p_{w s i}}{\Delta t_{i}\left(C_{2}-\left(1 / \Delta t_{i}\right)\right)^{2}}\right)\right. \\
& \left.\quad \times\left(\frac{\Delta p_{w s i}}{\left(1-\left(1 / C_{2} \Delta t_{i}\right)\right)}-f\left(C_{2}\right)-m\left(C_{2}\right) \log \left(\Delta t_{i}\right)\right)\right\} . \\
& =0 .
\end{aligned}
$$

The roots of (A.7) can be found via the following algorithm:

$$
C_{2(i+1)}=C_{2(i)}-\frac{X\left(C_{2}\right)}{X^{\prime}\left(C_{2}\right)},
$$

where

$$
\begin{aligned}
& X\left(C_{2}\right)=\sum_{i=1}^{N}\left\{\left(\frac{\Delta p_{w s i}}{\Delta t_{i}\left(C_{2}-\left(1 / \Delta t_{i}\right)\right)^{2}}\right)\right. \\
& \times\left(\frac{\Delta p_{w s i}}{\left(1-\left(1 / C_{2} \Delta t_{i}\right)\right)}-f\left(C_{2}\right)\right. \\
& \left.\left.-m\left(C_{2}\right) \log \left(\Delta t_{i}\right)\right)\right\} \\
& X^{\prime}\left(C_{2}\right)=\sum_{i=1}^{N}\left\{\left(-\frac{2 \Delta p_{w s i}}{\Delta t_{i}\left(C_{2}-\left(1 / \Delta t_{i}\right)\right)^{3}}\right)\right. \\
& \times\left(\frac{\Delta p_{w s i}}{\Delta t_{i}\left(C_{2}-\left(1 / \Delta t_{i}\right)\right)^{2}}\right. \\
& \times\left[\frac{\Delta p_{w s i}}{\left(1-\left(1 / C_{2} \Delta t\right)\right)}-f\left(C_{2}\right)\right. \\
& \left.\left.-m\left(C_{2}\right) \log \left(\Delta t_{i}\right)\right]\right) \\
& +\left(\frac{\Delta p_{w s i}}{\Delta t_{i}\left(C_{2}-\left(1 / \Delta t_{i}\right)\right)^{2}}\right) \\
& \times\left(-\frac{\Delta p_{w s i}}{\Delta t_{i}\left(C_{2}-\left(1 / \Delta t_{i}\right)\right)^{3}}-f^{\prime}\left(C_{2}\right)\right. \\
& \left.\left.-m^{\prime}\left(C_{2}\right) \log \left(\Delta t_{i}\right)\right)\right\}
\end{aligned}
$$

where the unknown functions are given by the following relations:

$$
f\left(C_{2}\right)=\frac{\beta u\left(C_{2}\right)-\alpha v\left(C_{2}\right)}{\beta^{2}-N \alpha}
$$

whose derivative is

$$
\begin{aligned}
f^{\prime}\left(C_{2}\right) & =\frac{\beta u^{\prime}\left(C_{2}\right)-\alpha v^{\prime}\left(C_{2}\right)}{\beta^{2}-N \alpha}, \\
m\left(C_{2}\right) & =\frac{N u\left(C_{2}\right)-\beta v\left(C_{2}\right)}{N \alpha-\beta^{2}},
\end{aligned}
$$

where its derivative is

$$
m^{\prime}\left(C_{2}\right)=\frac{N u^{\prime}\left(C_{2}\right)-\beta v^{\prime}\left(C_{2}\right)}{N \alpha-\beta^{2}}
$$

$$
u\left(C_{2}\right)=\sum_{i=1}^{N}\left\{\log \left(\Delta t_{i}\right) \frac{\Delta p_{w s i}}{\left(1-\left(1 / C_{2} \Delta t_{i}\right)\right)}\right\} \text {, }
$$


and after differentiation, it yields

$$
\begin{gathered}
u^{\prime}\left(C_{2}\right)=-\sum_{i=1}^{N}\left\{\frac{\log \left(\Delta t_{i}\right)}{\Delta t_{i}} \frac{\Delta p_{w s i}}{\left(C_{2}-\left(1 / \Delta t_{i}\right)\right)^{2}}\right\}, \\
v\left(C_{2}\right)=\sum_{i=1}^{N}\left\{\frac{\Delta p_{w s i}}{\left(1-\left(1 / C_{2} \Delta t_{i}\right)\right)}\right\}
\end{gathered}
$$

which has the following derivative:

$$
v^{\prime}\left(C_{2}\right)=-\sum_{i=1}^{N}\left\{\frac{1}{\Delta t_{i}} \frac{\Delta p_{w s i}}{\left(C_{2}-\left(1 / \Delta t_{i}\right)\right)^{2}}\right\} ;
$$

finally the values of $\alpha$ and $\beta$ parameters are given by the following formulas:

$$
\begin{gathered}
\alpha=\sum_{i=1}^{N}\left(\log \left(\Delta t_{i}\right)\right)^{2}, \\
\beta=\sum_{i=1}^{N} \log \left(\Delta t_{i}\right) .
\end{gathered}
$$

\section{B. General Formula for Inverse Problem}

The convolution of (6) yields

$$
\begin{aligned}
p_{s D}\left(t_{D}\right) & =\int_{0}^{t_{D}} K(\tau) p_{w D}\left(t_{D}-\tau\right) d \tau \\
& =\int_{0}^{t_{D}} K\left(t_{D}-\tau\right) p_{w D}(\tau) d \tau
\end{aligned}
$$

where

$$
K\left(t_{D}\right)=L^{-1}\left(\frac{1}{s \bar{q}(s)}\right),
$$

where $L^{-1}$ is the inverse Lapalce transform operator. $K\left(t_{D}\right)$ can be computed either from the Laplace transforms of $q_{D}\left(t_{D}\right)$ data, a curve-fitted equation of $q_{D}\left(t_{D}\right)$ data, or using another technique with a relation between $K\left(t_{D}\right)$ and $q_{D}\left(t_{D}\right)$. However, it would be time consuming to invert all the $q_{D}\left(t_{D}\right)$ data in Laplace space and transform it back to real space in accordance with (B.2). Once an approximation is obtained, it will be easy to compute $K\left(t_{D}\right)$ and integrate (B.1) to determine $p_{s D}\left(t_{D}\right)$. However, finding some approximation functions for $q_{D}\left(t_{D}\right)$ data may be difficult. We provide an approach to overcome this problem. This idea is based on finding another relation between $K\left(t_{D}\right)$ and $q_{D}\left(t_{D}\right)$; that is,

$$
\begin{aligned}
\ell(1) & =\frac{1}{s}=\frac{1}{s \bar{q}_{D}(s)} \bar{q}_{D}(s)=\ell\left(\int_{0}^{t_{D}} K(\tau) q_{D}\left(t_{D}-\tau\right) d \tau\right) \\
& =\ell\left(\int_{0}^{t_{D}} K\left(t_{D}-\tau\right) q_{D}(\tau) d \tau\right)
\end{aligned}
$$

or

$$
1=\int_{0}^{t_{D}} K(\tau) q_{D}\left(t_{D}-\tau\right) d \tau=\int_{0}^{t_{D}} K\left(t_{D}-\tau\right) q_{D}(\tau) d \tau .
$$

The other relations that can be used are

$$
\begin{aligned}
\ell\left(t_{D}\right) & =\frac{1}{s^{2}}=\frac{1}{s^{2} \bar{q}_{D}(s)} \bar{q}_{D}(s)=\ell\left(\int_{0}^{t_{D}} L(\tau) q_{D}\left(t_{D}-\tau\right) d \tau\right) \\
& =\ell\left(\int_{0}^{t_{D}} L\left(t_{D}-\tau\right) q_{D}(\tau) d \tau\right)
\end{aligned}
$$

or

$$
\begin{aligned}
t_{D} & =\int_{0}^{t_{D}} L(\tau) q_{D}\left(t_{D}-\tau\right) d \tau=\int_{0}^{t_{D}} L\left(t_{D}-\tau\right) q_{D}(\tau) d \tau \\
\ell(1) & =\frac{1}{s}=\frac{1}{s^{2} \bar{q}_{D}(s)} s \bar{q}_{D}(s)=\ell\left(\int_{0}^{t_{D}} L(\tau) q_{D}^{\prime}\left(t_{D}-\tau\right) d \tau\right) \\
& =\ell\left(\int_{0}^{t_{D}} L\left(t_{D}-\tau\right) q_{D}^{\prime}(\tau) d \tau\right)
\end{aligned}
$$

or

$$
1=\int_{0}^{t_{D}} L(\tau) q_{D}^{\prime}\left(t_{D}-\tau\right) d \tau=\int_{0}^{t_{D}} L\left(t_{D}-\tau\right) q_{D}^{\prime}(\tau) d \tau,
$$

where

$$
L\left(t_{D}\right)=\ell^{-1}\left(\frac{1}{s^{2} \bar{q}(s)}\right)
$$

Equation (B.4) can be used simultaneously with (B.1) to analyze the deconvolution problem.

Equation (11) can be written as

$$
\bar{p}_{s D}(s)=s \bar{p}_{w D}(s) \frac{1}{s^{2} \bar{q}_{D}(s)}
$$

or

$$
\begin{aligned}
p_{s D}\left(t_{D}\right) & =\int_{0}^{t_{D}} L(\tau) p_{w D}^{\prime}\left(t_{D}-\tau\right) d \tau \\
& =\int_{0}^{t_{D}} L\left(t_{D}-\tau\right) p_{w D}^{\prime}(\tau) d \tau .
\end{aligned}
$$

The applications of (B.6) and (B.8) are with (B.11).

For justifying the rate normalization method and material balance deconvolution, it can use (B.1), (B.4) ((B.11) can also be used with (B.6) or (B.8) for this goal) and generalized mean value theorem for integrals. This theorem is expressed as follows.

Theorem 1. Let $f$ and $g$ be continuous on $[a, b]$, and suppose that $g$ does not change sign on $[a, b]$. Then there is a point $c$ in $[a, b]$ such that

$$
\int_{a}^{b} f(t) g(t) d t=f(c) \int_{a}^{b} g(t) d t
$$


By Theorem 1, there are some values $c_{1}$ and $c_{2}$ between 0 and $t_{D}$ such that

$$
\begin{aligned}
p_{s D}\left(t_{D}\right) & =p_{w D}\left(c_{1}\right) \int_{0}^{t_{D}} K\left(t_{D}-\tau\right) d \tau, \\
1 & =q_{D}\left(c_{2}\right) \int_{0}^{t_{D}} K\left(t_{D}-\tau\right) d \tau .
\end{aligned}
$$

By setting $c_{1}=c_{2}=t_{D}$ and dividing the right and left side of (B.13), respectively, the rate normalization technique is developed. However, the values $c_{1}$ and $c_{2}$ are not equal to each other and are not equal to $t_{D}$ in general. This is the reason of error in rate normalization and material balance deconvolution methods. $c_{1}$ and $c_{2}$ are less than $t_{D}$ in these methods for the duration of wellbore storage distortion during a pressure transient test. Since these conditions are approximately satisfied in material balance deconvolution, the results of material balance are more accurate and more confident than rate normalization.

\section{Nomenclature}

API: API gravity, ${ }^{\circ}$ API

$B_{o}: \quad$ Oil formation volume factor, RB/STB

$c_{t}$ : Total isothermal compressibility factor, psi $_{-1}$

$\mathrm{C}_{2}$ : Arbitrary constant, $\mathrm{hr}_{-1}$

$C_{D}$ : Wellbore storage constant, dimensionless

$C_{s}$ : Wellbore storage coefficient, bbl/psi

$h$ : Formation thickness, $\mathrm{ft}$

HTR: Horner time ratio, dimensionless

$k$ : $\quad$ Formation permeability, md

$K: \quad$ Kernel of the convolution integral

$L: \quad$ Kernel of the convolution integral

$N_{p}$ : Cumulative oil production, bbl

$p: \quad$ Pressure, $p s i$

$p_{a}: \quad$ Normalized pseudopressure, $\mathrm{psi}$

$\bar{p}: \quad$ Average reservoir pressure, $\mathrm{psi}$

$p_{D}$ : Formation pressure, dimensionless

$p_{d p}:$ Dewpoint pressure, psi

$p_{i}$ : Initial reservoir pressure, $\mathrm{psi}$

$p_{s D}$ : Formation pressure including skin, dimensionless

$p_{s}: \quad$ Formation pressure including skin, psi

$p_{w D}:$ Pressure draw down, dimensionless

$p_{w f}$ : Flowing bottom hole pressure, psi

$p_{w s}:$ Shut-in bottom hole pressure, psi

$q_{D}:$ Sandface flow rate, dimensionless

$q_{g}:$ Gas flow rate, Mscf/D

$q_{0}$ : Oil flow rate, STB/D

$r_{w}$ : Wellbore radius, $\mathrm{ft}$

$s: \quad$ Laplace variable

S: $\quad$ Skin factor

$t: \quad$ Time, hr

$t_{D}:$ Time, dimensionless

$t_{p}$ : $\quad$ Production time, $\mathrm{hr}$

T: $\quad$ Reservoir temperature, ${ }^{\circ} \mathrm{F}$
$T_{d p}:$ Dewpoint temperature, ${ }^{\circ} \mathrm{F}$

$\alpha$ : Explicit deconvolution variable, dimensionless

$\beta$ : Beta deconvolution variable, dimensionless

$\gamma_{g}:$ Gas gravity $($ air $=1.0)$

$\lambda: \quad$ Interporosity flow coefficient of dual porosity reservoir

$\phi$ : Porosity of reservoir rock, dimensionless

$\mu_{g}:$ Gas viscosity, $\mathrm{cp}$

$\mu_{o}$ : Oil viscosity, $\mathrm{cp}$

$\omega$ : Storativity ratio of dual porosity reservoir

-: Laplace transform of a function

': Derivative of a function.

\section{Conflict of Interests}

The authors declare that there is no conflict of interests regarding the publication of this paper.

\section{References}

[1] Y. Cheng, W. J. Lee, and D. A. McVay, "Fast-Fourier-transformbased deconvolution for interpretation of pressure-transienttest data dominated by Wellbore storage," SPE Reservoir Evaluation and Engineering, vol. 8, no. 3, pp. 224-239, 2005.

[2] M. M. Levitan and M. R. Wilson, "Deconvolution of pressure and rate data from gas reservoirs with significant pressure depletion," SPE Journal, vol. 17, no. 3, pp. 727-741, 2012.

[3] Y. Liu and R. N. Horne, "Interpreting pressure and flow-rate data from permanent downhole gauges by use of data-mining approaches," SPE Journal, vol. 18, no. 1, pp. 69-82, 2013.

[4] O. Ogunrewo and A. C. Gringarten, "Deconvolution of well test data in lean and rich gas condensate, and volatile oil wells below saturation pressure," in Proceedings of the SPE Annual Technical Conference and Exhibition, Document ID: 166340MS, New Orleans, La, USA, September-October 2013.

[5] R. C. Earlougher Jr., Advances in Well Test Analysis, vol. 5 of Monogragh Series, SPE, Richardson, Tex, USA, 1977.

[6] F. Kucuk and L. Ayestaran, "Analysis of simultaneously measured pressure and sandface flow rate in transient well testing," Journal of Petroleum Technology, vol. 37, no. 2, pp. 323-334, 1985.

[7] M. Onur, M. Çinar, D. IIk, P. P. Valkö, T. A. Blasingame, and P. Hegeman, "An investigation of recent deconvolution methods for well-test data analysis," SPE Journal, vol. 13, no. 2, pp. 226247, 2008.

[8] F. J. Kuchuk, M. Onur, and F. Hollaender, "Pressure transient test design and interpretation," Developments in Petroleum Science, vol. 57, pp. 303-359, 2010.

[9] A. C. Gringarten, D. P. Bourdet, P. A. Landel, and V. J. Kniazeff, "A comparison between different skin and wellbore storage type-curves for early-time transient analysis," in Proceedings of the SPE Annual Technical Conference and Exhibition, Paper SPE 8205, Las Vegas, Nev, USA, 1979.

[10] A. C. Gringarten, "From straight lines to deconvolution: the evolution of the state of the art in well test analysis," SPE Reservoir Evaluation and Engineering, vol. 11, no. 1, pp. 41-62, 2008.

[11] J. A. Cumming, D. A. Wooff, T. Whittle, and A. C. Gringarten, "Multiple well deconvolution," in Proceedings of the SPE Annual 
Technical Conference and Exhibition, Document ID: 166458MS, New Orleans, La, USA, September-October 2013.

[12] O. Bahabanian, D. Ilk, N. Hosseinpour-Zonoozi, and T. A. Blasingame, "Explicit deconvolution of well test data distorted by wellbore storage," in Proceedings of the SPE Annual Technical Conference and Exhibition, Paper SPE 103216, pp. 4444-4453, San Antonio, Tex, USA, September 2006.

[13] J. Jones and A. Chen, "Successful applications of pressure-rate deconvolution in the Cad-Nik tight gas formations of the British Columbia foothills," Journal of Canadian Petroleum Technology, vol. 51, no. 3, pp. 176-192, 2012.

[14] D. G. Russell, "Extension of pressure buildup analysis methods," Journal of Petroleum Technology, vol. 18, no. 12, pp. 1624-1636, 1966.

[15] R. E. Gladfelter, G. W. Tracy, and L. E. Wilsey, "Selecting wells which will respond to production-stimulation treatment," in Drilling and Production Practice, API, Dallas, Tex, USA, 1955.

[16] M. J. Fetkovich and M. E. Vienot, "Rate normalization of buildup pressure by using afterflow data," Journal of Petroleum Technology, vol. 36, no. 13, pp. 2211-2224, 1984.

[17] J. L. Johnston, Variable rate analysis of transient well test data using semi-analytical methods [M.S. thesis], Texas A\&M University, College Station, Tex, USA, 1992.

[18] A. F. van Everdingen, "The skin effect and its influence on the productive capacity of a well," Journal of Petroleum Technology, vol. 5, no. 6, pp. 171-176, 1953.

[19] W. Hurst, "Establishment of the skin effect and its impediment to fluid flow into a well bore," The Petroleum Engineer, pp. B6B16, 1953.

[20] J. A. Joseph and L. F. Koederitz, "A simple nonlinear model for representation of field transient responses," Paper SPE 11435, SPE, Richardson, Tex, USA, 1982.

[21] F. J. Kuchuk, "Gladfelter deconvolution," SPE Formation Evaluation, vol. 5, no. 3, pp. 285-292, 1990.

[22] A. F. van Everdingen and W. Hurst, "The application of the laplace transformation to flow problems in reservoirs," Journal of Petroleum Technology, vol. 1, no. 12, pp. 305-324, 1949.

[23] D. Bourdet, T. M. Whittle, A. A. Douglas, and Y. M. Pirard, "A new set of type curves simplifies well test analysis," World Oil, pp. 95-106, 1983.

[24] D. F. Meunier, C. S. Kabir, and M. J. Wittmann, "Gas well test analysis: use of normalized pseudovariables," SPE Formation Evaluation, vol. 2, no. 4, pp. 629-636, 1987. 


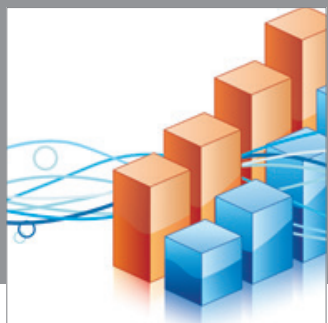

Advances in

Operations Research

mansans

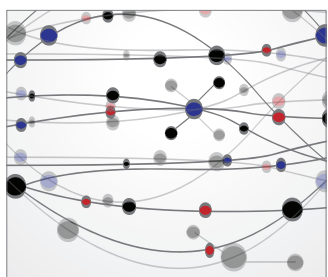

The Scientific World Journal
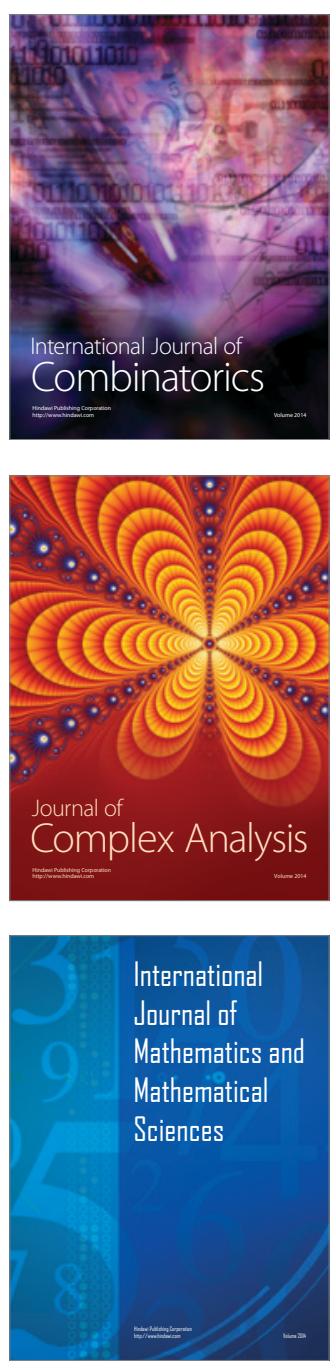
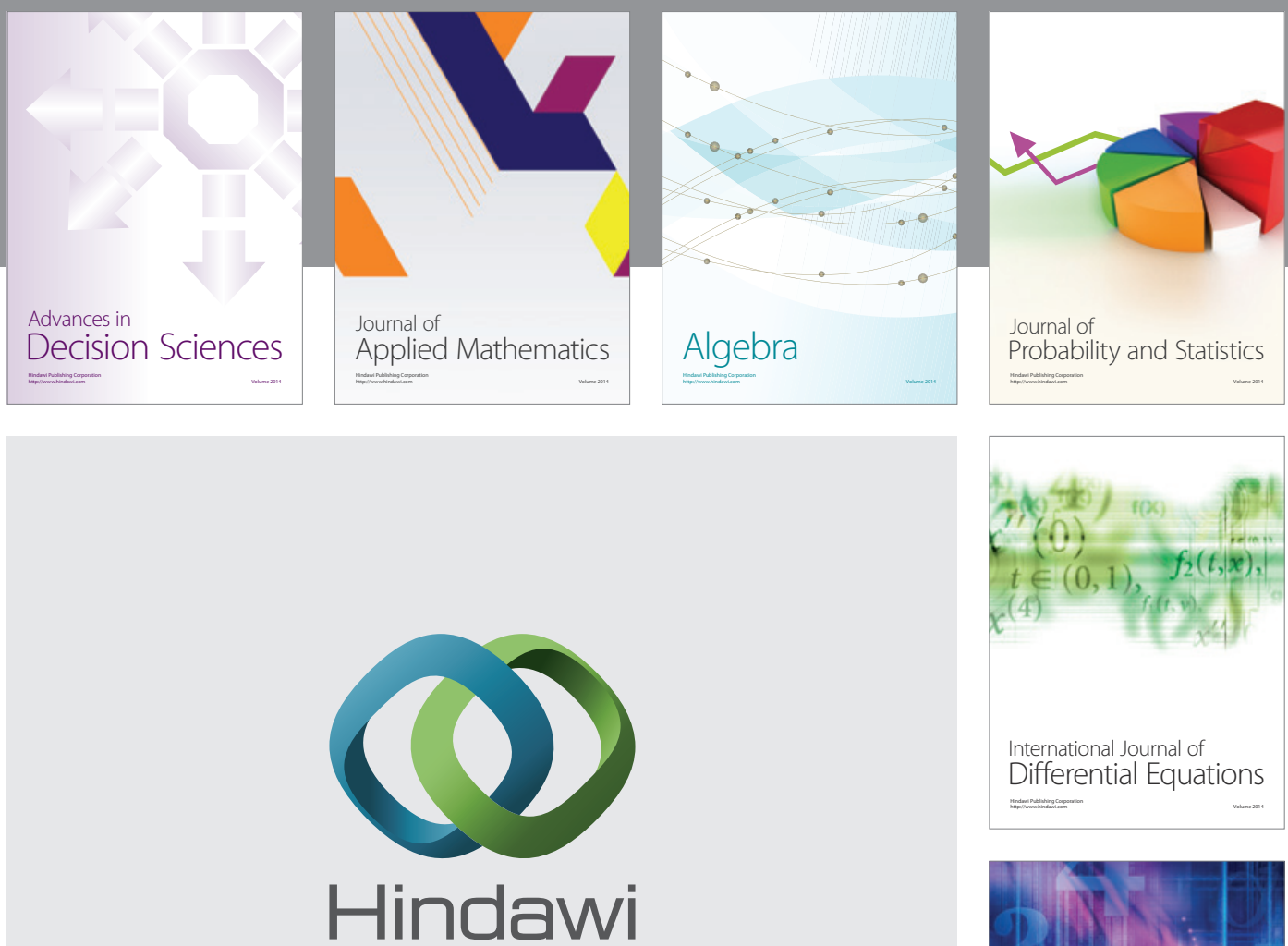

Submit your manuscripts at http://www.hindawi.com
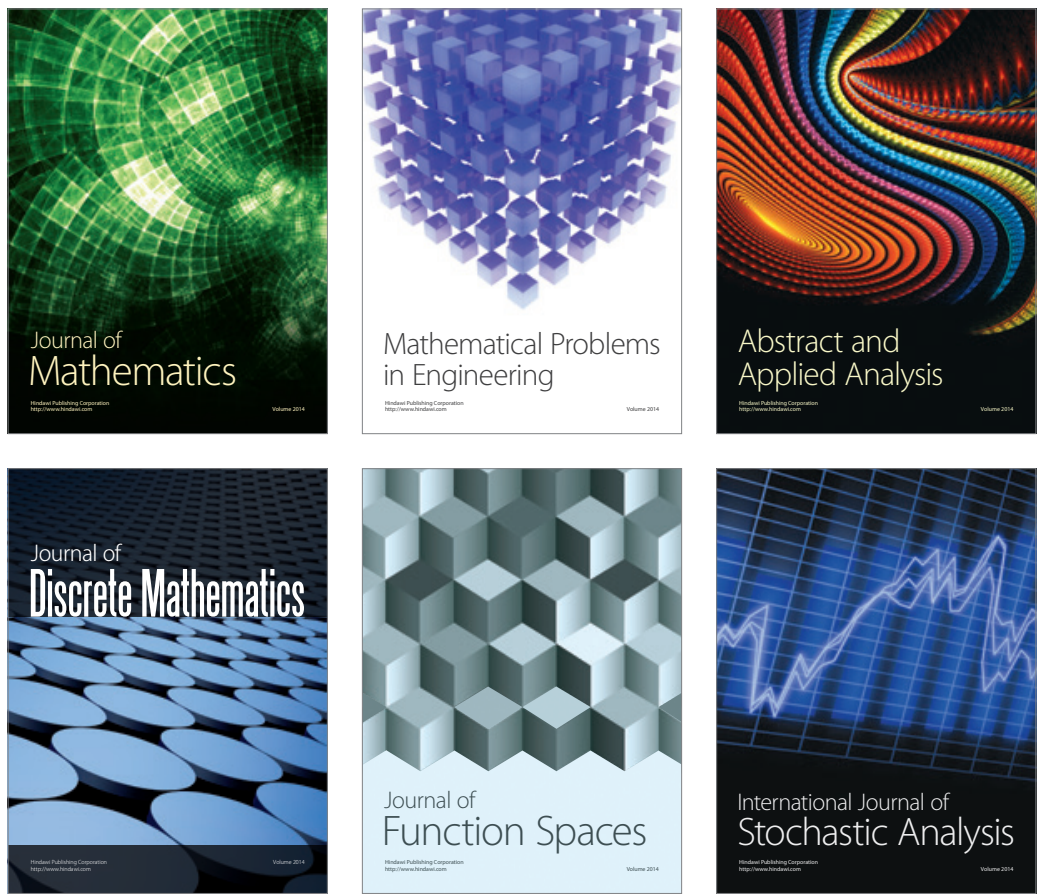

Journal of

Function Spaces

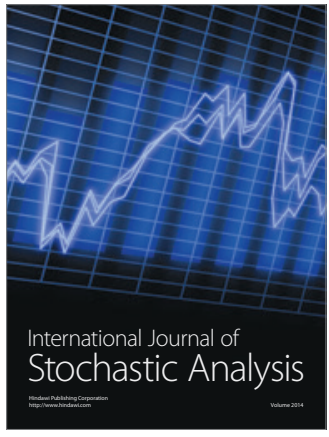

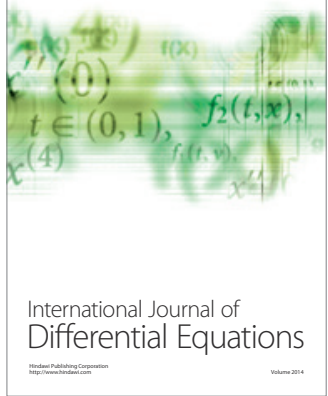
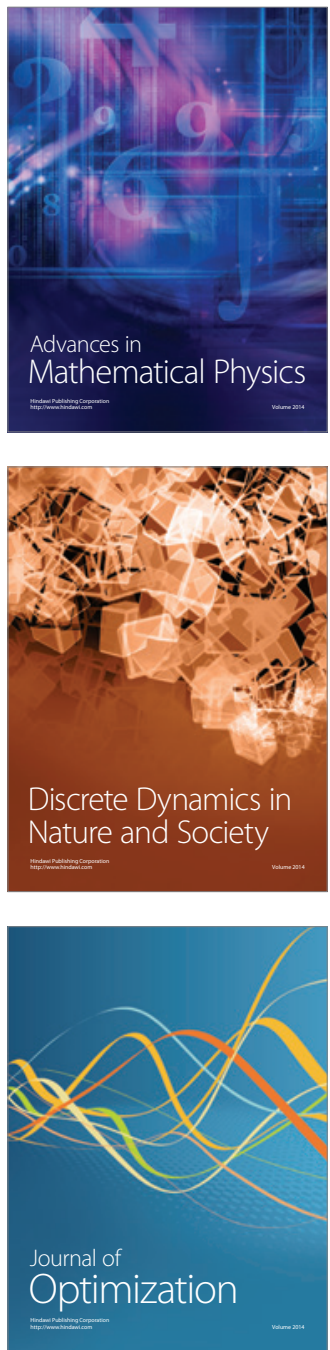